\title{
APPLICATION OF INTEGRATED PROJECT DELIVERY PRACTICES IN RESIDENTIAL CONSTRUCTION
}

\author{
Giuseppe Jenkins ${ }^{1}$, James P. Smith ${ }^{2}$, Evan Bingham ${ }^{3}$, and Justin Weidman ${ }^{4}$
}

\begin{abstract}
Application of Integrated Project Delivery (IPD) principles has been widely recognized and studied in complex projects across the United States. However, OAEC participants have argued that traditional delivery approaches are sufficient to efficiently preserve value on projects of smaller scales and decreased complexity. The purpose of this research is to see how Integrated Project Delivery (IPD) principles and practices can be used on high end custom residential construction projects to increase the collaboration and efficiency of the project team.

A case study was conducted on a custom home project to observe how and what IPD principles were used. Observations, interviews, and a survey were used to collect qualitative data from participants as part of the case study. Findings indicate that IPD principles and practices can be effectively utilized on custom residential projects. In addition, the research found that those involved found the experience to be positive and beneficial to their overall success on the project.
\end{abstract}

\section{KEYWORDS}

Integrated project delivery, collaboration, complexity, process, residential construction..

\section{INTRODUCTION}

Integrated Project Delivery (IPD) has been globally implemented and utilized for several years now on large commercial projects such as hospitals, office buildings and sports arenas (e.g., Aslesen et al. 2018, Dargham et al. 2019, Gomez et al. 2018). Traditionally, when constructing a building the owner hires an architect to draw the plans and design the building. Once sufficiently complete, the owner takes those plans and goes out to bid. Traditional delivery can result in waste and minimal collaboration because all parties have different objectives (Wang et al. 2008). In contrast IPD brings key stake holders together sooner in order to align objectives and goals and find solutions to problems before they happen and when it is still easy and comparatively inexpensive to fix (Nofera et al., 2011).

1 Graduate Student (MS), Brigham Young University, Provo, UT, USA, seppe21@gmail.com, orcid.org/0000-0002-8673-902X

2 Assistant Prof., Construction and Facilities Management, Brigham Young Unviersity, Provo, UT, USA, james smith@byu.edu, orcid.org/0000-0001-8925-5680

3 Assistant Prof., Construction and Facilities Management, Brigham Young Unviersity, Provo, UT, USA, evan_bingham@byu.edu, orcid.org/0000-0001-6636-5609

4 Assistant Prof., Construction and Facilities Management, Brigham Young Unviersity, Provo, UT, USA, justinweidman@,byu.edu, orcid.org/0000-0002-4280-8134 
Although IPD has been effectively implemented in the commercial construction sector, the residential sector has seen minimal adoption of this method. While there are notable differences between commercial and residential construction, many of the basic ideas and processes are the same. The hypothesis for this research is that IPD principles can be implemented on residential projects to improve project outcomes for key stakeholders. This general hypothesis was broken down into 3 basic research questions:

1. What IPD principles are being applied to residential projects?

2. How are the identified IPD principles being applied?

3. How do project participants perceive the impact of applied IPD principles?

Improved project outcomes for key stakeholders would include a decrease in waste, financial savings, reduced delivery time, and better experiences and deliverables for the owner. To test this hypothesis, a case study of a high end custom single family home was conducted to assess the impact of applied IPD principles.

\section{LITERATURE REVIEW}

Kent and Becerik-Gerber (2010) distributed a survey that was designed to target a wide range of professionals in the construction industry and to determine the level of awareness, experience, and interest of the respondents regarding IPD. Despite industry interest and some level of documentation regarding positive impacts on projects, the number of IPD projects was still relatively small. However, IPD is becoming increasingly popular and more organizations are expressing interest in its apparent benefits to the OAEC industry (El Asmar et al. 2013). Ibrahim and Hanna (2019) used an analysis of key performance indicators on 109 different projects to show that more collaborative delivery methods such as IPD showed statistically significant improvements in key areas of assessment.

Resistance to IPD adoption commonly comes from the owner or upper management and likely stems from risk associated with unknown processes. Educating owners and others by providing literature, presentations, or other means can help overcome these fears. Azhar (2014) found that public sector owners view IPD characteristics as beneficial and agree that IPD can improve project delivery effectiveness. They suggest that while IPD is still relatively new to public sector construction, it will continue to receive increasing attention despite contractual and statutory limits and a general lack of industry experience with IPD.

Matthews and Howell (2005) researched how implementing a lean delivery method, like IPD, will help maximize value and minimize waste. They believe that normal contractual agreements stifle cooperation and innovation, and reward individual contractors for both reserving good ideas, and optimizing their performance at the expense of others and the project. However, a Cho and Ballard (2011) study also provided some evidence that IPD projects did not show significantly different performance from projects that did not adopt IPD.

\section{KEY IPD CHARACTERISTICS}

The American Institute of Architects (AIA 2007) defines IPD as "a project delivery approach that integrates people, systems, business structures, and practices into a process that collaboratively harnesses the talents and insights of all project participants to optimize project results, increase value to the owner, reduce waste, and maximize efficiency through all phases of design, fabrication and construction." IPD is a method by 
which projects are organized and executed typically characterized by the following (adapted from Lee et al. 2014):

- Co-location of team members

- Liability waivers among key participants

- A multi-party contract

- Early involvement of key participants

- Jointly developed project goals

- Lean principles

- Collaborative decision making and goal definition

- BIM

- Intensified Planning

- Financial transparency

- Mutual respect and trust

- Open Communication and willingness to collaborate)

- Shared risks and rewards

All the above characteristics are typically incorporated in projects that are considered "full IPD". Many projects in the U.S., however, are only able to implement select elements of the full IPD package. For ease of analysis, we will consider two common approaches to implementing IPD: 1) IPD and 2) IPD-lite (a.k.a IPD-ish). IPD-lite projects attempt to bridge the comfort gap between traditional delivery and full IPD delivery. Typically, the absence of a multi-party contract with shared risk/reward is a key differentiating factor between the two approaches (BD\&C 2011), but IPD-lite projects could, in theory, implement varying components of IPD at differing levels. Lee (2013) found that projects using even basic IPD principles and practices saw positive results including increased efficiency and collaboration.

Lee (2013) identified a few very interesting and relevant conclusions regarding the impact of IPD implementation. This work suggests that short term immediate changes can be made to implement some IPD principles without having to resort to major structural changes. Additionally, even within federal government work, full implementation of IPD will likely be extremely difficult, but not entirely impossible.

\section{METHODOLOGY}

The initial literature review for this project consisted of an on-line search of two scientific databases and Google Scholar. After realizing that these databases were missing an abundance of relevant literature, the researcher also accessed the database of proceedings created by the International Group for Lean Construction (iglc.net).

Case study research is often used in studies seeking to answer the questions of "how" and "why" since these usually deal with documenting unique processes (Yin 2017). Case studies focus on the uniqueness of a singular case coming to know the particulars of that case and then taking what is learned and generalizing it for application in other situations (Stake 1995). Case study research is also a good choice when the topic has limited research resources from which to draw (Fox-Wolfgramm 1997). Residential projects claiming or attempting any level of IPD implementation are very rare so a case study approach allowed us to analyze these uncommon, practice-based situations.

The research was done in collaboration with the general contractor, who has been implementing IPD principles in residential projects since 2016. Several data collection methods were used including observations of key meetings, two surveys, and individual interviews with project management personnel. Qualitative data was collected through 
open-ended questions, allowing the respondents to answer freely. Survey data was analyzed for basic descriptive statistics to provide some additional information.

Survey respondents included project managers, foreman and superintendents of the trade partners working for the sponsoring contractor. Respondent selection was simply based on participation in the process. The survey was sent out to 25 respondents, of which 21 responded $(\mathrm{n}=21)$, at the end of the initial co-location meeting for the project, and again at the half-way point co-location meeting for the project. Following the co-location meetings the attendees were sent a link to the on-line survey, and asked to fill it out before leaving. Sending the surveys at the end of the co-location meetings allowed amininistrator of the survey to make sure the respondents understood the topic and any confusion could be clarified. The survey was distributed via email to the participants. The surveys were administered approximately two weeks apart and happened during the design phase prior to construction beginning on the project.

Observational data was collected by attending the referenced co-location meetings to understand how these principles were being implemented and to see how those involved responded. The researcher sat in during the meetings to take notes but was not an active participant. The meetings were not audio/video recorded.

Interviews were also conducted with two senior project managers for the general contractor to understand how IPD concepts were being implemented. These discussions were also used to understand the timeline and big picture of using IPD principles. This allowed us to understand how those overseeing the whole project perceived the benefits of using this method as well as the problems associated with using IPD principles.

\section{FINDINGS}

\section{Case Study SPecifics}

For this research the author collaborated with an award-winning nationally recognized home builder that builds high end custom homes primarily in the intermountain west region, focusing on Utah, Idaho, Wyoming and Colorado areas. These custom projects range from $\$ 600,000$ into the millions.

The project chosen for the case study was a custom home being constructed in Southern Idaho in the United States. The value for this home is estimated between $\$ 700,000$ to $\$ 800,000$ with an estimated square footage of approximately 300 total square meters (3200 square feet). Construction duration was expected to be approximately seven months . The number of trades on the project is estimated to be between 20-30 by project completion. The general contractor/project management team consisted of a project manager and a superintendent with supporting help from the office staff. This project was in the developmental stages when this research project was undertaken which allowed for research personnel to participate in the critical first co-located project kick-off meetings. Preferred trade partners were hired using traditional contracts, but selection was based on their previously proven willingness to participate in the collaborative approach adopted by the contractor.

\section{Adopted Process}

Typical residential construction processes begin when the home buyer chooses a contractor to build a custom home. Initial discussions take place between the owner and the contractor and preliminary plans are created with the general contractor showing basic floor layout, size, aesthetics, etc. At this point, the case study's IPD process diverges from 
the traditional approach as seen in Figure 1. Key trade partners needed for the project are involved early on during the design phase. In this case, the structural, HVAC, plumbing, and electrical contractors were asked to consult on the design prior to bids being awarded.

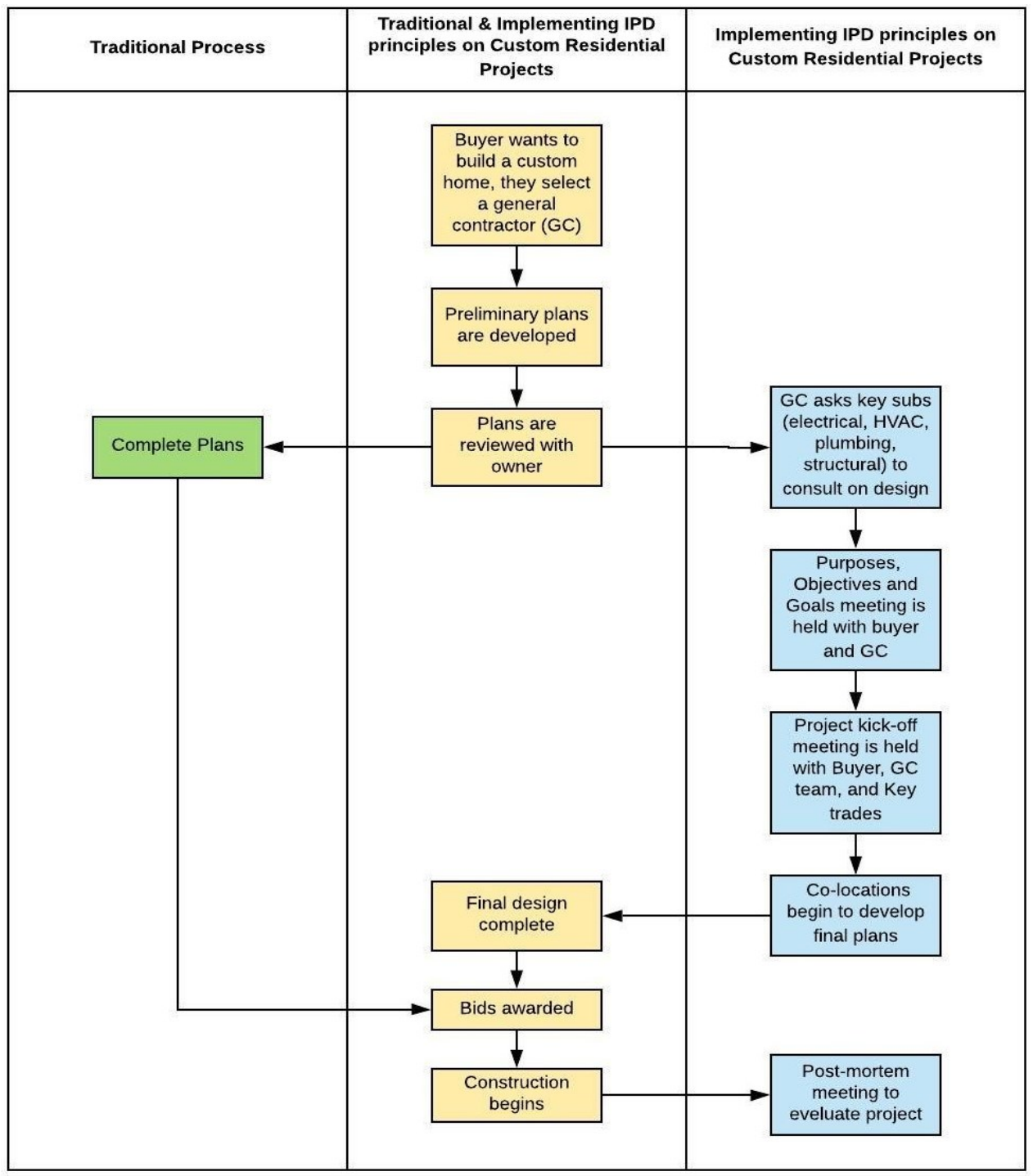

Figure 1: Process Overview

\section{Setting Project Purposes, Objectives and Goals}

To begin the project a meeting was held with the owner and the general contractor's project management team to establish the purpose, objectives and goals for the project. This discussion focused on what the owner, in this case a home buyer, was looking to get out of their new home. The meeting took place in a conference room at the general contractor's office, participants sat around a table with a large screen at one end that was used to present topics and review items. Topics centered around what needed to be accomplished for them to feel the project had been a success, for example staying in a budget, creating a space that they could relax and unwind, and key features (i.e. value) the owners would like to have. From this discussion an overall purpose was established to help guide decisions for the rest of the project. Then, a few specific objectives and goals were agreed upon by the group that would be the measure of success. Based on 
conversations with the project management team, the author found that the purpose, objectives and goals vary widely based on the owner and their circumstance. Establishing these items was deemed critical by the project management team in meeting the owner's expectations and as a result having a successful project.

\section{Project Kick-off Meeting}

The project kick-off meeting took place following the purposes and objectives meeting and brought together the owner, the general contractor project management team, and the core trades for this project. For this meeting the owners both sat in the front row of seating along with the project manager (PM), estimator, and superintendent for the project. Participants from the various trades sat in the remaining seating, no seating assignments were made. The PM led the meeting inviting the owners to participate on key items throughout the meeting. During this meeting the purpose, objectives, and goals that were created previously were discussed with the whole team. This allowed the owner to communicate their vision and what they were hoping to accomplish. Success for the project was defined and the main objectives were reviewed, aligning the goals of all involved and defining success to ensure that everyone was working for the same purpose.

\section{Co-Location Meetings}

Co-locations were used to get the major team players on the project in the same room in order to discuss and resolve problems. On this project the author observed several colocation meetings over the course of several weeks as the project was getting started. Because this project was still in the beginning stages, meetings typically only involved one to three trade partners, the owner, and the general contractor PM team.

Agendas for each meeting were sent out several days in advance to all participants for them to review and have adequate time to prepare any materials necessary. This also allowed the agenda to be revised before the meeting if someone had an item that needed to be added. Agenda items were kept to a minimum to keep these meetings under two hours in length. Of the meetings observed, all stayed within two hours. The agenda was created by the general contractor's project management team and the project manager was responsible for running the meeting. Primary objectives include discussing the various elements of the project and refine the design, plans, and estimate. Once the construction plans are complete, bids were solicited and awarded. Throughout the project co-location meetings can be used for team building, to overcome a specific issue, review work done, make adjustments, and continue to plan/coordinate upcoming work.

Meetings began with brief introductions of those in attendance. These introductions included their name, company, and their scope of work. After introductions the purpose of the meeting and agenda were quickly reviewed by the project manager. This helped focus the group and refresh everyone of the objectives, purpose and outcomes of the colocation meeting. The agenda items were then addressed in sequence with the project manager driving the meeting. As items were discussed assignments were made and noted, as were resolutions and plans made.

For this case study the home buyer (owner) attended each meeting as did the general contractor project management team - in this case the project manager and the superintendent. The other attendees consisted of one to two representatives from the trade partner participating in that meeting. For example, one of the co-locations was to discuss and review the mechanical, electrical, and plumbing (MEP) for the project. Each MEP trade partner had a foreman or superintendent, someone who would oversee the day-today work, and typically a project manager in attendance. 
For the case study, the set up of the room used for the Co-location meetings was very intentional (see example setup in Figure 2). The room was set up in way that allowed for flexibility and re-arranging to enable smaller groups to break off and work. It was recommended that tables with wheels be used to allow for easy spatial adjustments.

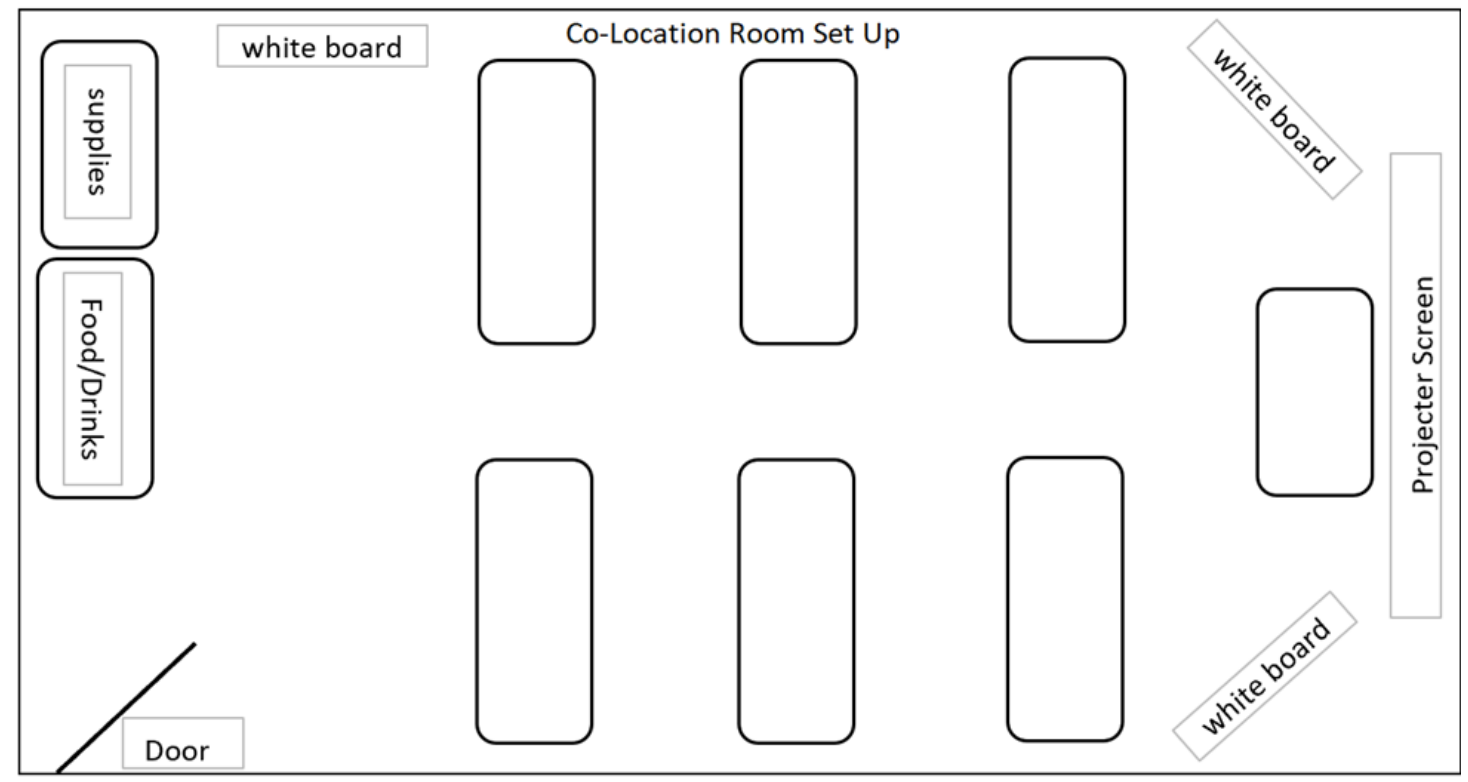

Figure 2: Case Study Big Room Set Up for Co-Location

Co-location meetings were held in the same room every time, in this case at the general contractor's offices. The room was big enough to fit up to around 30 people. The colocation room was set up specifically for hosting co-location meetings so that it was available when needed. Tables, chairs, and white boards were provided for use by the participants. Other materials were also available including sticky notes, markers, notepads and pens/markers. All the tables, chairs and whiteboards had wheels so they could be moved and rearranged quickly as needed. A web camera was at the front of the room so those attending via computer could see the other attendees, a projector with was also available for use. For reviewing plans or other documents a camera was attached to a table to give an overhead view. This allowed those on the video call to see the plans as well so they could see what was being done and give input.

\section{Participant FeedBack}

The survey asked respondents to give specific feedback about what they felt was positive about the experience (PLUS) as well as what could be improved (DELTA). PLUS comments were summarized under three categories: (1) accountability, (2) communication, and (3) finding solutions. Similarly, the DELTA comments were summarized under three categories: (1) time management, (2) plans, and (3) follow up.

Generally comments related to accountability were centered around the sharing of accountability and being collectively responsible for solutions. This improved accountability was perceived to lead to greater efficiency and cooperation on the project. The feedback related to communication also seems to support that with the comments focusing on getting things out in the open, getting input from trades on the best way to move forward with construction, and allowing the design team to more effectively collaborate with the construction team. The largest portion of feedback concerned finding 
solutions. The trades feel this process aided them, and the team as a whole, to find solutions to problems early, resulting in a streamlined construction process. It also indicates that trades appreciate the opportunity to give feedback and find solutions to those problems as the project progresses. Select participant feedback examples from each category are included in Table 1.

Table 1: Participant Feedback - PLUS

\begin{tabular}{|c|c|}
\hline $\begin{array}{l}\text { Identified } \\
\text { Themes }\end{array}$ & Responses \\
\hline \multirow[t]{3}{*}{ Accountability } & Making everyone accountable to each other, at least to pay attention. \\
\hline & Getting everyone on board with joint-accountability. \\
\hline & $\begin{array}{l}\text { Having the ability to voice issues experienced during the last } \\
\text { construction phase, and having the opportunity to talk with related trade } \\
\text { partners and management upfront in hopes of finding solutions to those } \\
\text { issues so going forward, everyone can perform their tasks with greater } \\
\text { efficiency. }\end{array}$ \\
\hline \multirow[t]{4}{*}{ Communication } & Getting things out in the open. \\
\hline & $\begin{array}{l}\text { The direct input from the different people involved in the project, General } \\
\text { Contractor being receptive to Trade Partner input }\end{array}$ \\
\hline & $\begin{array}{l}\text { Understanding client needs and desires better to produce a final project } \\
\text { people are excited about being part of. }\end{array}$ \\
\hline & It helps to meet with the architect and engineer face to face. \\
\hline \multirow[t]{5}{*}{$\begin{array}{l}\text { Finding } \\
\text { Solutions }\end{array}$} & $\begin{array}{l}\text { Great having input up front with the designers and other subcontractors. } \\
\text { I think it will help solve some of the problems we encountered on the last } \\
\text { phase. }\end{array}$ \\
\hline & Everyone working together to reach the same goal. \\
\hline & Feedback from door installer on door issues and solutions to implement. \\
\hline & Working together to find the most efficient way to get the project built. \\
\hline & Talking through the previous problems. \\
\hline \multirow[t]{5}{*}{ Other } & Positive team mentality, better work environment. \\
\hline & Open mindedness and new ideas for future phases. \\
\hline & Being part of the team. \\
\hline & We may have a great set of drawings. \\
\hline & Good flow to the project, scheduling has been good. \\
\hline
\end{tabular}

$100 \%$ of survey respondents $(n=21)$ found being involved early to be beneficial to them. In a slightly more specific question, $100 \%$ of the respondents also said they felt this process created an environment where they were able to be more efficient.

On the DELTA side, time management was the biggest area of concern with comments centered around the amount of time meetings took. Most feedback, from the trades, in this category had some relation to wanting it to be less time consuming and balancing the level of detail required. Another area of concern was that trades who were only needed for small portions of the meeting were required to stay for the entire meeting. Plans were another area that came up several times in the comments. This feedback focused on making sure that the plans were up-to-date for the meeting allowing them a 
clear idea of what was needed from them. Another concern was making sure the changes made were communicated to those that those changes affected. Which ties in the follow up category. Follow up comments focused on communicating what was discussed during the meeting and communicating any changes effectively and quickly to those involved (see Table 2).

Table 2: Participant Feedback - DELTAS

\begin{tabular}{|c|c|}
\hline $\begin{array}{l}\text { Identified } \\
\text { Themes }\end{array}$ & Suggestions \\
\hline \multirow[t]{4}{*}{$\begin{array}{l}\text { Time } \\
\text { Management }\end{array}$} & $\begin{array}{l}\text { To move through things a little quicker and when we come to a } \\
\text { stumbling block that's really up to the engineer or the architect, let them } \\
\text { have adequate time to come up with solutions and then we can regroup } \\
\text { and look at the recommended solutions. }\end{array}$ \\
\hline & $\begin{array}{l}\text { It's hard to block out an entire day for meetings, but if it must be then it } \\
\text { must be. }\end{array}$ \\
\hline & Trying not to get into so many details with a large group. \\
\hline & $\begin{array}{l}\text { Have those trade partners with less imperative, time consuming, } \\
\text { concerns participate earlier in the round tables so they don't have to sit } \\
\text { through the entire session. }\end{array}$ \\
\hline \multirow[t]{4}{*}{ Plans/Drawings } & Focus on creating a clear, better set of plans. \\
\hline & Up-to-date set of plans for review would be great. \\
\hline & Finishing the site work package earlier so I can provide better budgets. \\
\hline & $\begin{array}{l}\text { Notify trades if they are effected by any changes to plans in addition to } \\
\text { updating sheets on plan grid. }\end{array}$ \\
\hline \multirow[t]{3}{*}{ Follow Up } & $\begin{array}{l}\text { Just want to make sure we implement everything we talked about and } \\
\text { not make this week a waste. Build on it and keep the momentum. }\end{array}$ \\
\hline & $\begin{array}{l}\text { Follow up with meeting notes, white board images, and/or a summary of } \\
\text { what was discussed. }\end{array}$ \\
\hline & Keeping the communication going throughout the project. \\
\hline Other & More snacks for the people that are there all day $;$ \\
\hline
\end{tabular}

\section{Observations}

From the observations of the meetings there were several key take-aways. First, it is critical to get the owner to buy into the process. During the Project Purposes, Objectives, and Goals meeting a considerable amount of time was spent explaining the process, the benefits, and why this process helps achieve better results. Second, discussion about expectations and a clear definition of project success must be stimulated and facilitated by the general contractor. This provides a clear direction that can be presented during the kick-off meeting with the trades. Third, it is important to have the owner present at the kick-off meeting to interact with the trades/team and help present their vision and expectations. Finally, during co-location meetings the contractor must engage the trades by obtaining and validating their input and encouraging open dialogue.

\section{Interviews}

The president of the division for the contractor and a vice president of a collaborating company were interviewed. These two have been refining the process described for several years now and given several presentations on this process at conferences. 
However, this is the first time these efforts have been documented for an academic publication. These interviewees were quick to point out that the process used by the general contractor is not necessarily a prescriptive process, each project has different circumstances that may require adjustment. The timeline, tools, and practices used should be flexible and used as needed to fit a specific project's needs, even if it isn't a full IPD implementation. One other item from the interview highlighted that the owners of the case study project highly recommended this process to others.

\section{IMPACT ON COST?}

Exact numbers were not available for use in this research but there were several impacts to cost worth noting. As mentioned, during the early stages key trades consulted on the project's design. These trades were in some cases paid for their time. Because of this, initial costs are typically higher than on projects using a traditional method. However, interviewees claim that the overall savings from using IPD principles were clear from previous projects and off set the upfront costs. Additionally, per conversations with the general contractor, because of the nature of custom houses the majority of savings are found in increased efficiency during construction due to less change orders and re-work.

\section{CONCLUSIONS}

The hypothesis for this research is that IPD principles can be implemented on residential projects to improve project outcomes for key stakeholders. The following research questions were based on the hypothesis:

1. What IPD principles are being applied to residential projects?

2. How are the identified IPD principles being applied?

3. How do project participants perceive the impact of applied IPD principles?

The results of the case study indicate that using IPD principles on high end custom residential projects can be done successfully with the proper application of principles and practices. Qualitatively, there is a positive impact on efficiency and cost. In addition, survey results indicate that the trade partners feel this process is also beneficial to them.

Feedback from trade partners on the survey suggests that they generally like using IPD principles because it gives them more input during design. This allows them to make suggestions that can help them be more efficient and provide a better finished product to the owner. Having them involved early also helps limit costly change orders throughout the project because those issues that lead to change orders are likely to be caught earlier. Identifying issues early is key because the team has more control and options available to solve them then they would later in the project. Costs associated with the changes can also be more easily controlled the earlier they are identified.

While this case study did not incorporate all elements of a full IPD project, the following key characteristics from the literature were successfully implemented and are recommended as a meaningful and manageable starting point for interested parties: 1) early involvement of team members, 2) collaborative decision making, 3) liability waivers, 4) jointly developed project goals, 5) mutual respect and trust, co-location as possible, and 6) financial transparency. These principles were implemented through the use of various tools including co-locations in big room settings, scrums, setting project purposes, objectives and goals, collaborative scheduling, and seeking and implementing feedback after the co-location meetings. The main IPD practices found on full IPD projects that were not used include, multi-party contracts, shared risk/reward, and co-location of major 
team members for the duration of the project. This project would also not meet the definition of IPD-Lite. The authors suggest that IPD principles can be implemented on high end custom residential project through a variety of practices and tools. Because each project is different in scope and circumstance there is not a one size fits all solution. The research would suggest that the best way to proceed would be to evaluate the needs of the project and decide what practices and tools are most appropriate. For those readers looking to begin IPD implementation in residential projects, the authors recommend a few initial efforts. First, begin with a Purpose, Objectives and Goals Meeting with the owner to establish a vision for the project. Establishing these will provide a guide for the project management team as well as the trade partners throughout the project as they make decisions. This also allows expectations to be set for what needs to be accomplished for the project to be a success.

Second, the early involvement of key trades to help with the design process to help identify and resolve problems and create a more complete set of plans before construction begins. This process accomplished through co-location meetings is key to having success. This not only allows for input from the experts but can help build a team culture. Creating a culture that cultivates collaboration and trust, something that cannot be contracted, is what this entire process hinges on. Early involvement of the trades then serves two purposes - input into the design leads to better plans with less issues, and creating the right culture. Both elements lead to greater efficiency. The atypical up front costs should be discussed and justified in early meetings with the owner.

Third, as part of co-locations or periodically throughout the duration of the project the team should have wellness checks. These are a time to discuss what is going well, what is not, and make adjustments and plans as needed. The purpose of this is to make sure processes that are working are continued, processes that are not are stopped or adjusted, and a chance to allow new ideas to be expressed and implemented. At the completion of a project it is recommended to have a post mortem to evaluate the project as a whole noting lessons learned and what worked well for application on future projects.

\section{NeXT STEPS}

This research focused on how IPD principles are being applied on high end custom residential projects. Future research should attempt to quantify the impact of IPD implementation on project completion on time and on budget in the residential market. Additionally, research opportunities exist related to the application of IPD principles and practices on smaller and/or production residential jobs. Finally, a more rigorous analysis of the engagement of trades on traditional projects compared to IPD projects would inform possible future adopters.

\section{REFERENCES}

AIA (2007). "Integrated Project Delivery: A Guide.” Retrieved May 16, 2018, from http://www.msa-ipd.com/IPD_Guide_2007.pdf

Aslesen, A.R., Nordheim, R., Varegg, B., and Lædre, O. (2018). "IPD in Norway" In: Proc. 26th Annual Conference of the International. Group for Lean Construction (IGLC), González, V.A. (ed.), Chennai, India, pp. 326-336. DOI: doi.org/10.24928/2018/0284.Available at: www.iglc.net.

Azhar, N. (2014). "Integrated Construction Project Delivery System in the U.S. Public Sector: An Information Modeling Framework." FIU Electronic Theses and Dissertations. 1567. https://digitalcommons.fiu.edu/etd/1567 
BD\&C (2011). “IPD lite': Do you need a contract to deliver an integrated project?" Retrieved March 14, 2019, from https://www.bdcnetwork.com/'ipd-lite'-do-youneed-contract-deliver-integrated-project

Cho, S., \& Ballard, G. (2011). "Last Planner and Integrated Project Delivery." Lean Construction Journal.

Dargham, S., Bou Hatoum, M., Tohme, M., and Hamzeh, F., (2019). "Implementation of Integrated Project Delivery in Lebanon: Overcoming the Challenges.” In: Proc. 27th Annual Conference of the International. Group for Lean Construction (IGLC), Pasquire C. and Hamzeh F.R. (ed.), Dublin, Ireland, pp. 917-928. DOI: https://doi.org/10.24928/2019/0242. Available at: <www.iglc.net>.

El Asmar, M., Hanna, A. S., and Loh, W. Y. (2013). "Quantifying performance for the integrated project delivery system as compared to established delivery systems." Journal of Construction Engineering and Management, 139(11), 04013012.

Gomez, S., Ballard, G., Naderpajouh, N., Ruiz, S. (2018). "Integrated Project Delivery for Infrastructure Projects in Peru." In: Proc. 26th Annual Conference of the International. Group for Lean Construction (IGLC), González, V.A. (ed.), Chennai, India, pp. 452-462. DOI: doi.org/10.24928/2018/0506. Available at: www.iglc.net.

Fox-Wolfgramm, S. J. (1997). "Towards developing a methodology for doing qualitative research: The dynamic-comparative case study method." Scandinavian Journal of Management, 13(4), 439-455.

Ibrahim, MW., and Hanna, AS. (2019). "Comparative Analysis of Project Performance Between Different Project Delivery Systems." In: Proc. 27th Annual Conference of the International. Group for Lean Construction (IGLC), Pasquire C. and Hamzeh F.R. (ed.), Dublin, Ireland, pp. 663-674. DOI: https://doi.org/10.24928/2019/0183. Available at: $<$ www.iglc.net $>$.

Kent, D. C., \& Becerik-Gerber, B. (2010). "Understanding Construction Industry Experience and Attitudes toward Integrated Project Delivery." Journal of Construction Engineering and Management. Retrieved May 2, 2018, from https://ascelibrary.org/doi/abs/10.1061/(ASCE)CO.1943-7862.0000188.

Kulkarni, A., Rybkowski, Z. K., and Smith, J. (2012). "Cost comparison of collaborative and IPD-like project delivery methods versus non-collaborative project delivery methods," In: Proceedings of the 20th annual conference for the International Group for Lean Construction; July 17-22, 2012: San Diego, CA, U.S.A.

Lee, C.S. (2013). "Implementation of Integrated Project Delivery on Department of Navy Military Construction Projects." UNLV Theses, Dissertations, Professional Papers, and Capstones. 1940. https://digitalscholarship.unlv.edu/thesesdissertations/1940

Lee, H., Anderson, S. M., Kim, Y. \& Ballard, G. (2014). “Advancing Impact of Education, Training, and Professional Experience on Integrated Project Delivery." Practice Periodical on Structural Design and Construction, 19(1), 8-14.

Matthews, O., and Howell, G. A. (2005). "Integrated Project Delivery An Example Of Relational Contracting." Lean Construction Journal, 2(1), 46-51.

Nofera, W., Korkmaz, S., Miller, V., and Toole, T. M. (2011). "Innovative features of integrated project delivery shaping project team communication." In: The 2011 Engineering Project Organizations Conference Proceedings.

Stake, R. E. (1995). "The art of case study research." Sage Publications.

Wang, J., Kang, X., and Tam, V. (2008) "An investigation of construction wastes: an empirical study in Shenzhen." Journal of Engineering, Design and Technology, 6(3), pp.227-236, https://doi.org/10.1108/17260530810918252 
Yin, R. K. (2017). "Case study research and applications: Design and methods." Sage Publications. 